\title{
Foucault y la arqueología de la política. Tras las huellas de un método inconcluso
}

\section{[Foucault and the Archaeology of Politics. Following the Footprints of an Unfinished Method]}

\author{
PABlo MARTín MÉNDEZ \\ Universidad Nacional de Lanús \\ Consejo Nacional de Investigaciones Científicas y Técnicas \\ pmmendez@unla.edu.ar
}

\begin{abstract}
Resumen: Este artículo busca reconstruir los principios metodológicos de la "arqueología de la política" que Foucault introduce hacia el final de L'archéologie du savoir aunque nunca desarrolla de manera explícita. La exposición se organiza en tres ejes. En primer lugar, explora los puntos de cruce y las posibles diferencias entre la arqueología del saber y la arqueología de la política. En segundo lugar, examina el lugar que podrían ocupar los "programas" y las "racionalidades de gobierno" en la arqueología de la política. Por último, propone a la razón de Estado, el liberalismo y el neoliberalismo como posibles campos de investigación para el desarrollo de esa arqueología. Con ello se pretende obtener una "grilla de inteligibilidad" cuyo punto de partida no sean las categorías universales habitualmente utilizadas por el análisis jurídico-político procedente de los siglos XVI y XVII, sino las prácticas de los gobernantes y los gobernados.
\end{abstract}

Palabras clave: universales, prácticas discursivas, programa, racionalidad de gobierno, grilla de inteligibilidad

\begin{abstract}
This article proposes to reconstruct the methodological principles of the "archaeology of politics" mentioned by Foucault at the end of L'archéologie du savoir, although never explicitly continued. The text is organized in three complementary axes. First, it explores the crossing points and possible differences between the archaeology of knowledge and the archaeology of politics. Second, it investigates the place that "programs" and "government rationalities" might take in the archeology of politics. Finally, it porposes the reason of State, liberalism and neoliberalism as possible research fields for the development of said archeology. Therefore, this article seeks to obtain a "grid of intelligibility" whose basis are not the universal categories usually used by legal-political analysis from the 16th and 17th centuries, but the practices of the governing and governed.
\end{abstract}

Key words: universals, discursive practices, program, rationality of government, grid of intelligibility

\section{Introducción}

A menudo se ha hecho pasar a Foucault como un pensador desinteresado por la política y los fenómenos políticos. Su negativa a hablar 
sobre "el" Estado, "la" soberanía o "la" justicia acreditaría tal sospecha. ¿Cómo pensar la política si no es en relación con aquello que tenemos en común? ¿Cómo analizarla sin hacer referencia a la sociedad en que vivimos, a las normas y valores que compartimos o a las coacciones que se nos imponen en calidad de ciudadanos miembros del Estado? Hoy sabemos que las propuestas de Foucault desembocan en algo más que una simple negación del análisis político. De hecho, la cuestión no pasa por negar o restar valor a dicho análisis, sino por reinventarlo en su forma y en sus posibles alcances. A ese proyecto general obedece una serie de herramientas teórico-metodológicas que Foucault desarrolló durante los años setenta y parte de los ochenta. Me refiero a propuestas como la "microfísica del poder", la "gubernamentalidad" o la "ontología del presente", entre otras. Las consecuencias que de allí se desprenden son enormes y, sin duda, no han terminado de asimilarse por completo. En última instancia, lo que se pone en juego no es sólo un conjunto de concepciones filosófico-políticas; es también una manera de concebir la política o, mejor todavía, de descifrar sus condiciones, posibilidades y efectos.

Hay no obstante una propuesta de análisis que se encuentra explícitamente ligada a la política pero que aún no ha recibido la suficiente atención. Quizá ello se deba a que Foucault la deja en suspenso o bien parece continuarla por otros medios. La propuesta se encuentra en las páginas finales de L'archéologie du savoir, donde Foucault advierte que, además de un análisis arqueológico orientado hacia la epistemología y la configuración histórica de las ciencias, cabe la posibilidad de realizar unas arqueologías de la sexualidad, de la pintura y de la política. Se ha dicho que Foucault avanzó en la primera y tercera cuestión (Castro 2016). ¿No son Surveiller et punir y los tres volúmenes de Historie de la sexualité un claro ejemplo al respecto? ¿Y qué decir sobre los cursos dictados en el Collège de France entre las décadas de 1970 y 1980? Cierto es que, más allá de algunas indicaciones sueltas, no hay ningún lugar en el que Foucault desarrolle las implicaciones metodológicas de lo que denomina "otras arqueologías". Esto vale sobre todo para la arqueología de la política, que no debería entenderse como el simple prototipo de la microfísica y la gubernamentalidad, sino como un método en gran parte independiente, con sus propias características y potencialidades. Así pues, si nos mantenemos en un nivel arqueológico-político, ¿cuáles serían los saberes en juego? ¿Qué clase de prácticas discursivas se describirían? ¿A qué formaciones o regularidades se accedería? Según Foucualt, el intento de responder estos interrogantes: 
haría aparecer un saber político que no es del orden de una teorización secundaria de la práctica, ni es una aplicación de la teoría. Puesto que está regularmente formado por una práctica discursiva que se despliega entre otras prácticas y se articula sobre ellas, no es una expresión que "refleje" más o menos en forma adecuada cierto número de "datos objetivos" o de prácticas reales. Entra desde el principio en el campo de las diferentes prácticas donde encuentra al mismo tiempo su especificación, sus funciones y la red de sus dependencias. (Foucault 1969, p. 254; a menos que se indique lo contrario, las traducciones de Foucault son mías)

Este artículo intenta seguir la huella de una arqueología de la política, aunque sin pretender desarrollar una sistematización y jerarquización de los conocimientos disponibles acerca de Foucault. Al contrario, se trata de avanzar en la construcción de una herramienta metodológica tan necesaria como perfectible a través de diversos aportes. Tal es la tarea que parecería exigir el presente, sobre todo donde los análisis inspirados en Foucault suelen prescindir de las herramientas arqueológicopolíticas al suponer que las mismas se encuentran integradas y hasta superadas por sus investigaciones posteriores. Así, no sólo se relega la centralidad de las prácticas discursivas en la construcción de la realidad política y social, sino que además se rehabilita una lectura de la obra foucaultiana por etapas, como si ésta fuese un conjunto de compartimentos estancos tendientes a superarse entre sí. ${ }^{1}$

De ahí la estrategia que desarrollo en este artículo: más que desentrañar la arqueología de la política en textos como la Histoire de la folie, Naissance de la clinique o Les mots et les choses, propongo reconstruirla siguiendo otros momentos y lugares de la obra foucaultiana. Si bien en este punto se abren varios caminos, opté por concentrarme en los trabajos de la segunda mitad de la década de 1970, en especial en la conferencia "La pusière et la nuge" (1978) y los cursos del Collège de France titulados Sécurité, territoire, population (1978) y Naissance de la biopolitique (1979). Es aquí donde Foucault parecería continuar por

${ }^{1}$ La lectura en cuestión, que alimentó en parte el mismo Foucault y reforzaron más tarde Dreyfus y Rabinow 2017, divide la obra del primero en tres etapas: la "arqueología" (1961-1969), la "genealogía" (1971-1976) y la "gubernamentalidad" (1978-1984) (Morey 2008). Ello es correcto siempre y cuando no nos lleve a suponer que la apertura de una nueva etapa implica la interrupción abrupta de las anteriores. Antes bien, a través de sus libros, cursos y entrevistas, Foucault construye campos de investigación que no se sustituyen ni se superan entre sí, sino que se interconectan a través de innumerables diagonales: "soy como el cangrejo, me desplazo lateralmente" (Foucault 2004, p. 80). He desarrollado estas posibilidades de lectura en Méndez 2015.

Revista de Filosofía Diánoia, vol. 65, no. 84 (mayo-octubre de 2020) e-ISSN: 1870-4913 • DOI: https://doi.org/10.22201/iifs.18704913e.2020.84.1603 
otros medios la arqueología de la política que anunció hacia fines de los años sesenta. ${ }^{2}$ Por cierto, esos trabajos no son absolutamente fieles a la terminología y a las categorías de análisis de L'archéologie du savoir. En todo caso, lo que ofrecen es una vía para analizar las formas de integración y funcionamiento de las prácticas discursivas en distintos ensamblajes gubernamentales. Los siguientes apartados se ordenan de acuerdo con dicha hipótesis de lectura buscando releer algunas de las categorías arqueológicas más importantes en el marco de los estudios sobre la gubernamentalidad.

En primer lugar, exploro los puntos de cruce y las posibles diferencias entre la arqueología del saber y la arqueología de la política en lo relativo a sus modalidades de descripción y sus respectivas unidades de análisis. En segundo lugar, investigo el carácter que adoptarían los "saberes" correspondientes a una arqueología de la política. Esta indagación me llevará a destacar el papel que desempeñan las "programaciones" de la sociedad (Foucault 1994d) en el marco del análisis arqueológico-político. Se trata de positividades que no coinciden exactamente ni con la teoría ni con la realidad empírica. No coinciden con la teoría porque son otra cosa que el producto de la imaginación o la voluntad esclarecida de unos individuos; pero tampoco coinciden con "la" realidad como sustrato más profundo y determinante que las voluntades y las imaginaciones. $\mathrm{Al}$ igual que las prácticas discursivas, las programaciones ensamblan un conjunto de cálculos, técnicas y estrategias de distinta procedencia sin necesidad de expresar o traducir algo que ocurriría en otra parte. De aquí se desprende una tercera cuestión por analizar, y es que las programaciones no deben abordarse como prescripciones o recetas de gobierno bien sistematizadas, sino como la línea de acceso a unas formas de plantear problemas, objetos y metas gubernamentales. Dicho de otra manera: mientras que en la arqueología del saber la descripción de las prácticas discursivas permite acceder al "archivo", entendido como la ley de lo que puede y lo que no puede ser dicho en un sistema de enunciabilidad, en la arqueología de la política la descripción de las programaciones permite acceder a la "racionalidad de gobierno" presente en una determinada coyuntura histórica. Con esto me referiré al modo hacer pensables y decibles (Gordon 1991; Castro-Gómez 2010), tanto para gobernantes como para gobernados,

\footnotetext{
${ }^{2}$ Sin duda, la interconexión entre la arqueología y los estudios sobre la gubernamentalidad es una opción posible entre otras tantas. Hay asimismo conexiones con las investigaciones genealógicas y, en particular, con la "microfísica del poder", cuyo análisis exhaustivo excede el marco de este artículo y que aquí sólo se plantearán como sugerencia para estudios posteriores.
} 
unos problemas/interrogantes sobre la realidad política y social, unos objetos de intervención que se definen en función de esos interrogantes y unos fines de gobierno que buscan dar solución a los mismos. En cuarto y último lugar ofrezco un recorrido breve de la "razón de Estado", el "liberalismo" y el "neoliberalismo" analizados por Foucault en los cursos Sécurité, territoire, population y Naissance de la biopolitique, y que propongo en este artículo como posibles campos de investigación para el desarrollo de una arqueología de la política. De acuerdo con mis argumentos finales, la arqueología de la política nos permitiría obtener una "grilla de inteligibilidad" cuyo punto de partida no serán ya las categorías universales que habitualmente utiliza el análisis político, sino las mismas prácticas discursivas de gobernantes y gobernados.

Ahora bien, para comprender los alcances y los límites del análisis arqueológico-político, es necesario aclarar cómo se define la política desde la perspectiva foucaultiana y observar algunas de sus diferencias con las concepciones vigentes en la tradición de los análisis filosóficos y sociológicos.

\section{Los universales no existen, tampoco en la política}

El pensamiento de Foucault es sin duda heterogéneo y discontinuo, aunque ofrece algunos criterios básicos que no abandona casi nunca y que lo atraviesan de manera diagonal. Aquí me detendré en uno de los más importantes, y es la idea de que los universales no existen. Desde la perspectiva propuesta por Foucault, no existe "lo estatal", "lo económico" o "lo social" como totalidades que podamos presuponer en la base de nuestras investigaciones o restituir en su punto de llegada. Esta postura se traduce en una "elección metodológica" explícita: "dejar de lado como objeto primero, primitivo, ya dado, una serie de nociones como, por ejemplo, el soberano, la soberanía, el pueblo, los sujetos, el Estado, la sociedad civil: todos esos universales que el análisis sociológico, así como el análisis histórico y el análisis de la filosofía política, utilizan para dar cuenta efectivamente de la práctica gubernamental" (Foucault 2004 , p. 4). En otras palabras, cuando se analizan las prácticas mediante las cuales los hombres intentan dominarse entre sí, conviene no hacer como si las mismas estuviesen enmarcadas de antemano en algo llamado sociedad, soberanía o Estado. La cuestión consiste en evitar que estos términos se transformen en el a priori de las prácticas que analizamos. ¿Por qué hemos de suponer que las prácticas de dominación responden sin más a las necesidades del Estado? ¿Cuál es la razón para creer que nuestras costumbres, hábitos y conductas provienen de

Revista de Filosofía Diánoia, vol. 65, no. 84 (mayo-octubre de 2020) e-ISSN: 1870-4913 • DOI: https://doi.org/10.22201/iifs.18704913e.2020.84.1603 
la sociedad como instancia sobredeterminante? Según Foucault, "con ello no se tiene en cuenta ni la complejidad de los mecanismos, ni su especificidad, ni los apoyos, complementariedades, y a veces bloques, que esta diversidad implica" (Foucault 1994b, p. 232). Pero hay que avanzar con cuidado; no es que se trate de negar las categorías que comúnmente se utilizan en la filosofía política o el análisis sociológico, sino de abordarlas desde una perspectiva diferente. Al menos en principio, se trata de preguntar a partir de qué prácticas localizadas y concretas, así como también de qué apoyos y articulaciones entre las mismas, es realmente posible hablar sobre el Estado, la sociedad o la economía.

El método de Foucault parece apuntar hacia algo más que una mera negación de los universales. En todo caso, el desafío pasa por "analizar, en su forma históricamente singular, cuestiones de alcance general" (Foucault 1994f, p. 577). ¿Qué significa esto? ¿Cómo se puede articular lo históricamente singular con cuestiones de alcance general? No existen "lo estatal", "lo económico" o "lo social" como universales, pero sí estrategias políticas que surgen de las prácticas concretas, que están acompañadas por ciertas tecnologías de poder y que responden, en cada lugar donde aparecen, a la necesidad de coordinar y de dar sentido a unas relaciones de fuerza. Allí donde las fuerzas resisten o intentan dominarse, donde aparece un nuevo procedimiento para segregar a los locos, para tratar la enfermedad o para vigilar con mayor intensidad a los cuerpos, se dibuja un trayecto relacionado con el sentido de la razón y de la sinrazón, la forma de la vida y de la muerte, la configuración del orden en oposición al desorden (Foucault 1994c). Por eso Foucault puede rechazar las concepciones de la política impuestas por el pensamiento filosófico-jurídico de los siglos XVI y XVII —esto es, las concepciones que presentan a la política como lo que determina en última instancia- y a la vez afirmar que "todo es político": "cada relación de poder reenvía, como a su efecto, pero también como a su condición de posibilidad, a un campo político del que forma parte. Decir que 'todo es político' quiere decir esta omnipresencia de las relaciones de fuerza y su inmanencia en un campo político" (Foucault 1994b, p. 233).

Entre un punto y otro, entre las relaciones de fuerza y el campo político del que forman parte, a veces centellea un mundo, una sociedad y unos hombres posibles, como un orden de cosas que jamás se consuma y que, no obstante, incide en las prácticas concretas. A esos órdenes inconclusos Foucault los denomina en ciertas ocasiones "programaciones": "se trata de un ensamblaje de prescripciones calculadas y razonadas según las cuales se deberían organizar unas instituciones, 
acondicionar unos espacios y regular unos comportamientos" (Foucault 1994d, pp. 27-28). A diferencia de lo que podría parecer a primera vista, las programaciones de las que habla Foucault están lejos de funcionar como una simple idealidad opuesta al devenir de las prácticas reales; por el contario, "estas programaciones inducen toda una serie de efectos en la realidad (lo que no quiere decir, evidentemente, que puedan ocupar su lugar): se cristalizan en unas instituciones, informan el comportamiento de los individuos, sirven de grilla a la percepción y la apreciación de las cosas" (Foucault 1994d, p. 29). Tales son las "positividades" descritas por la arqueología de la política: no "el" Estado, "la" economía o "la" sociedad como universales, sino unas programaciones entrelazadas con las prácticas.

En la medida en que son resultado de la práctica y a la vez tienen efectos en la práctica, las programaciones de sociedad adquieren a veces la forma de una "verdad" universal e incuestionable. Ello no implica que posean un alcance ilimitado; antes bien, las programaciones son siempre inconclusas, no sólo porque su realización encuentra innumerables obstáculos, sino porque están desde el principio abiertas a sucesivas desviaciones y transformaciones. De ahí que su descripción jamás permita acceder a algo así como la vida real del Estado o de la sociedad entendida en forma unívoca y absoluta. La cuestión consiste más bien en advertir que el Estado o la sociedad son sólo un proyecto entre otros tantos; el efecto de innumerables luchas que pueden alcanzar ciertos equilibrios o puntos de estabilización, pero que nunca se cierran por completo. Pues bien, la arqueología de la política apunta a mostrar dicha apertura.

\subsection{De la arqueología del saber a la arqueología de la política}

Para avanzar en la construcción de una arqueología de la política, es necesario advertir primero que ésta se sitúa en el límite de las descripciones y análisis de la episteme. ${ }^{3}$ Ello es así porque las prácticas discursivas pueden movilizar saberes en direcciones distintas a las de

\footnotetext{
${ }^{3}$ Según el prefacio de Les mots et les choses, la episteme es aquello que sale a la luz cuando se estudian las condiciones de posibilidad de nuestros conocimientos prescindiendo de criterios históricos como el progreso de la razón o el avance hacia la objetividad: "los conocimientos [...] hunden su positividad y manifiestan así una historia que no es la de su perfección creciente, sino la de sus condiciones de posibilidad; en esta historia, lo que debe aparecer son, en el espacio del saber, las configuraciones que dieron lugar a las diversas formas del conocimiento empírico. Más que una historia en el sentido tradicional de la palabra, se trata de una 'arqueología'” (Foucault 1966, p. 13).
} 
la ciencia, alcanzando umbrales estéticos o también políticos. Como señala Gilles Deleuze en su lectura de L'archéologie, el saber "es inseparable de tal y tal umbral en el que está incluido: incluso la experiencia perceptiva, incluso los valores de lo imaginario, incluso las ideas de la época o los elementos de la opinión común" (Deleuze 2008, p. 79). Lo cual se relaciona con una segunda cuestión más general, y es que el saber no se identifica necesariamente con los conocimientos científicos: "El saber no está involucrado solamente en las demostraciones, también puede estarlo en las ficciones, las reflexiones, los relatos, los reglamentos institucionales y las decisiones políticas" (Foucault 1969, p. 239). Describir el modo en que todo esto confluye en la formación de unos saberes políticos - vale decir, unos saberes que no ingresan en el umbral de la epistemologización, sino más bien de los conflictos, las estrategias y las prácticas de dirección de los comportamientos- es función de una arqueología de la política. Al cruzar este umbral ya no sacamos a la luz una episteme; lo que exponemos, en todo caso, son unas racionalidades de gobierno.

Ahora bien, para ingresar en dicho territorio hay que tomar ciertas precauciones. Comenzaré por lo más básico: cuando ponemos en suspenso al Estado, la economía o la sociedad como entidades sobredeterminantes, y exponemos en cambio unas racionalidades, ¿no estamos haciendo foco en el nivel de las "mentalidades" y las "estrategias individuales"? Más aún, ¿no entramos con ello en la vieja disputa entre las visiones holistas de los fenómenos sociales y el individualismo metodológico? Las respuestas son aquí concluyentes: prescindir de los universales no es quedarse con la racionalidad individual como base de cualquier descripción posible. Así como la arqueología de las ciencias prescinde del sujeto cognoscente cuando describe enunciados y formaciones discursivas, la arqueología de la política hace lo propio al describir sus positividades. Las racionalidades no hacen referencia a unos individuos capaces de plantear determinados fines y reflexionar sobre los recursos necesarios para alcanzarlos. Lejos estamos del domino científico, o con pretensiones de cientificidad, al que nos llevarían en algún punto las concepciones sociológicas extendidas entre Weber y el marxismo analítico.

De ahí que las racionalidades de gobierno no deban tomarse como unos "tipos ideales" construidos a partir de las conexiones de sentido que los sujetos asignan a sus acciones. Hay un nivel en el que esas racionalidades se vuelven perfectamente explícitas, donde no es necesario reinterpretar ni develar nada, puesto que todo surge desde los pequeños conflictos y los intentos por resolverlos. Así lo decía Foucault

Revista de Filosofía Diánoia, vol. 65, no. 84 (mayo-octubre de 2020) e-ISSN: 1870-4913 • DOI: https://doi.org/10.22201/iifs.18704913e.2020.84.1603 
a propósito de la "disciplina" y las programaciones disciplinarias analizadas en Surveiller et punir: "La 'disciplina' no es la expresión de un 'tipo ideal' (el del 'hombre disciplinado'); es la generalización y la puesta en conexión de técnicas diferentes que a su vez tienen que responder a unos objetivos locales (aprendizaje escolar, formación de ejércitos capaces de manejar el fusil)" (Foucault 1994d, p. 28). La arqueología de la política no es la continuación más o menos refinada de una Verstehen; sus formas de procedimiento y sus objetivos últimos poco tienen que ver con la pretensión de construir conocimiento a partir de las motivaciones subyacentes en los actores sociales. Otros son los saberes que aquí entran en juego.

La vía de acceso a las racionalidades de gobierno está en lo que Foucault denominaba "focos locales" de poder-saber:

$[\mathrm{P}]$ or ejemplo, las relaciones que se entablan entre penitente y confesor, o entre el fiel y el director de conciencia: allí, y bajo el signo de la "carne" que se debe dominar, diferentes formas de discurso — examen de sí mismo, interrogatorios, confesiones, interpretaciones, conversaciones- vehiculizan, en una especie de vaivén incesantes, formas de sujeción y esquemas de conocimiento. (Foucault 1976, p. 130)

Los focos de poder no se reducen necesariamente a los espacios de confesión, sino que también se refieren al espacio del manicomio, la prisión, la escuela, el taller y todos aquellos lugares donde los hombres intentan dominarse unos a otros. Son focos locales, regionales y dispersos que, por un lado, tienen sus procedimientos propios y sus tácticas particulares, mientras que, por el otro, están abiertos al juego de las resistencias y las transformaciones. Se trata, en términos de Deleuze, de núcleos inestables, no formados, de poder-saber.

De estos núcleos inestables, donde hay unas fuerzas que someten y otras que resisten, brotan saberes fragmentarios o discontinuos; saberes que resultan difíciles de sistematizar y jerarquizar en forma de conocimientos. Foucault ha señalado en más de una ocasión que la arqueología no analiza formas de conocimiento, sino que describe el saber entendido como:

[A]quello a partir de lo cual se construyen proposiciones coherentes (o no), se desarrollan descripciones más o menos exactas, se efectúan verificaciones, se despliegan teorías [...] lo previo de lo que revelará y funcionará como un conocimiento o una ilusión, una verdad admitida o un error denunciado, un conocimiento definitivo o un obstáculo superado. (Foucault 1969, p. 237)

Revista de Filosofía Diánoia, vol. 65, no. 84 (mayo-octubre de 2020) e-ISSN: 1870-4913 • DOI: https://doi.org/10.22201/iifs.18704913e.2020.84.1603 
El saber no se refiere a una capacidad adquirida en forma gradual y progresiva por unos sujetos, sino a la serie de articulaciones discursivas en las que éstos se encuentran insertos y de las que dependen. En términos de L'archéologie, son las operaciones que intervienen en la formación regular de los objetos, circunscribiéndolos, reagrupándolos o haciéndolos derivar unos de otros. Asimismo, son las coordinaciones y las subordinaciones discursivas que, más allá de la mentalidad o la conciencia de algunos individuos, dan lugar a los conceptos y los sistemas conceptuales. Por último, son las posibilidades de sistematizar un discurso mediante estrategias de apropiación, delimitación y exclusión de otros discursos. ${ }^{4} \mathrm{Si}$ esto es lo que describe la arqueología del saber, ¿qué le corresponde entonces a una arqueología de la política?

Veamos primero un par de detalles en común. Así como la arqueología del saber propone una descripción de las prácticas discursivas sin hacer referencia al cogito para situarse en cambio en el plano del "se dice", la arqueología de la política hace lo propio sin referirse a un sujeto dotado de poder. Tanto para un caso como para el otro, los individuos no son una instancia previa a las prácticas, operaciones y mecanismos desplegados; por el contrario, son un relevo de los mismos. Ello no implica que la arqueología pretenda sacar a la luz, mediante sucesivas y cada vez más profundas descripciones, la estructura determinante de las acciones individuales. En cierto modo, todo está en la superficie de las prácticas discursivas o, lo que es lo mismo, en la exterioridad constituida por sus relaciones y articulaciones. Por eso Foucault insiste en algo que a primera vista nos resultaría curioso, y es que la arqueología se dedica a describir positividades: "Analizar una formación discursiva es tratar un conjunto de actuaciones verbales a nivel de los enunciados y de la forma de positividad que los caracteriza; o más brevemente, es definir el tipo de positividad de un discurso" (Foucault 1969, p. 164). Pues bien, ¿̇cuáles serían las positividades que describe una arqueología de la política?

Lo que en la arqueología del saber es descripción de prácticas discursivas, en la arqueología de la política, es descripción de programaciones. Estas positividades no coinciden exactamente con las teorías políticas vigentes en un momento determinado ni con los datos supuestamente objetivos de la realidad. Son más bien prácticas discursivas que

\footnotetext{
${ }^{4}$ Véase al respecto la conferencia titulada L'ordre du discours, en la que Foucault sostiene que la crítica arqueológica "intenta definir las formas de exclusión, limitación y apropiación [de los discursos]; mostrar cómo se formaron, para responder a qué necesidades, cómo cambiaron y se desplazaron, qué coacciones ejercieron efectivamente, en qué medida fueron alterados" (Foucault 1971, p. 62).
} 
se articulan con otras prácticas, que dan lugar a ciertas regularidades y rarificaciones, que constituyen campos de inteligibilidad o de desciframiento político, hasta definir "lo que de la política puede devenir objeto de enunciación, las formas que esta enunciación puede adoptar, los conceptos que en ella se aplican, y las elecciones estratégicas que allí tienen lugar" (Foucault 1969, p. 254). Las programaciones funcionan como saberes en el sentido arqueológico de la palabra, aunque sin ingresar en los umbrales de epistemologización y cientifización. Lo que hay que preguntarse, entonces, es cómo se define un umbral político y cuáles son sus posibles efectos.

\section{2. ¿Qué son los saberes políticos?}

La arqueología de la política se desarrolla en un territorio muy particular: por un lado, rehúye a desentrañar las fuerzas o motivaciones que se ocultarían tras las prácticas - como la conciencia de clase, la visión profética de ciertos individuos, la ley de las revoluciones, etc.-, mientras que, por el otro, trata con elementos que jamás están simplemente dados y a su entera disposición. Al igual que la arqueología del saber, la arqueología de la política describe positividades que no son visibles pero que tampoco permanecen ocultas a nuestra mirada. Esta cuestión no es nada sencilla, pues se trata de poder ver y poder decir algo sobre el mismo entramado de prácticas que nos hace ver y hablar en términos políticos. ${ }^{5}$ De ahí que la descripción arqueológica requiera de una cierta "conversión de la mirada" buscando atravesar "esas transparencias familiares que, por no ocultar nada en su espesor, no se dan sin embargo con toda claridad" (Foucault 1969, p. 145).

Deleuze sostenía que, desde una perspectiva arqueológica, el saber se define como una combinación entre lo visible y lo enunciable: "El saber es un agenciamiento práctico, un 'dispositivo' de enunciados y de visibilidades [...]. Lo que equivale a decir que el saber sólo existe en función de 'umbrales' muy variados, que señalan otras tantas láminas, separaciones y orientaciones en el estrato considerado" (Deleuze 2008, p. 79). Para la perspectiva arqueológica, los enunciados no son palabras que signifiquen cosas o frases cargadas de un sentido objetivo, sino la función mediante la cual un conjunto de signos delimita — sin necesi-

\footnotetext{
${ }^{5}$ Como señalan Dreyfus y Rabinow, "estar tanto fuera como dentro del discurso que se estudia, compartiendo sus pretensiones significativas mientras se las deja en suspenso, es la ineluctable condición del arqueólogo" (Dreyfus y Rabinow 2017, p. 169). Es una condición que, según los mismos autores, habría conducido al "fracaso" del método arqueológico y a su sustitución por la genealogía.
} 
dad de remitirse a ninguna otra condición más que a su modalidad de existencia- unos dominios de objetos, unas funciones de sujeto y una relación con los demás campos de enunciados. Sucede lo mismo con las visibilidades, que no son sólo características o cualidades de las cosas, sino "formas de luminosidad creadas por la propia luz que sólo dejan subsistir las cosas o los objetos como resplandores, reflejos, centelleos" (Deleuze 2008, p. 80). Las visibilidades no están en la mirada de un sujeto; antes bien, son función de los esquemas arquitectónicos y de las formas de acondicionar el espacio. En las formas de acondicionar el espacio hospitalario de fines del siglo XVIII, Foucault encuentra las condiciones de surgimiento del "ojo clínico" como campo de percepción donde intervienen nuevos sistemas de registro, descripción y clasificación de las enfermedades, además de su integración en series numéricas y en estadísticas (Foucault 1963). Lo mismo vale para los manicomios, donde la locura se hace patente, evidente, perfectamente visible, así como las prisiones hacen patente al delincuente o los recintos escolares a la infancia.

El saber se liga a todo un arte de las distribuciones especiales que es también, como sugiere Deleuze, un modo de distribuir lo claro y lo oscuro, lo visto y lo no visto. Estas prácticas "no discursivas" no pueden reducirse a las prácticas discursivas analizadas por L'archéologie du savoir. En efecto, nunca se ve todo lo que se dice ni se dice todo lo que se ve. Si llevásemos esto al terreno de la arqueología, convendríamos igualmente en que los discursos médicos, psiquiátricos o penales no hablan sobre los reclusos de una manera similar a como se los ve en los hospitales, manicomios o prisiones. Foucault habría buscado demostrar tal disyuntiva en varias ocasiones, desde la Histoire de la folie hasta Naissance de la clinique, y de aquí hasta Surveiller et punir:

[L]a prisión como visibilidad del crimen no deriva del derecho penal como forma de expresión; procede de un horizonte completamente distinto, "disciplinario" y no jurídico; y el derecho penal produce sus enunciados de "delincuencia" independientemente de la prisión, como si siempre se viera obligado de decir, de alguna manera, esto no es una prisión. (Deleuze 2008, p. 91)

Se sabe que las prisiones no hacen lo que se dice o se espera de ellas, que su resultado más inmediato y visible no consiste en la corrección y reinserción de los individuos en la sociedad, sino en la producción del delincuente como sujeto de una permanente vigilancia. Por eso los espacios penitenciarios han sido desde el principio el blanco de innumera- 
bles reformas y propuestas de mejora; como si, en el límite, se intentase cerrar lo que siempre permanece abierto e inconexo.

Hay programas y proyectos que parecerían surgir de la necesidad misma de unir lo que se dice con lo que se ve, las prácticas discursivas con las no discursivas. Son rarezas que la historia de las ideas suele pasar por alto y que la arqueología de la política considera positividades privilegiadas. No por casualidad Foucault ha tenido tanto interés en el panóptico de Jeremy Bentham. En efecto, allí encontramos el sueño de zanjar la divergencia entre los enunciados y las visibilidades diciendo lo que un delincuente es incluso antes de que el delito se manifieste en determinados actos. El panóptico obedece a otra cosa que la simple necesidad de enmendar el mal que provocan algunos individuos; su objetivo consiste más bien en "hacer que éstos ni siquiera puedan actuar mal, ya que se sentirían sumergidos, inmersos, en un campo de visibilidad total donde la opinión de los otros, la mirada de los otros, el discurso de los otros, les impidan obrar mal o hacer daño" (Foucault 1994a, p. 196). No debemos confundir el panóptico con una extravagancia que sólo se aplica en ciertos contextos o circunstancias, y menos aún con una ilusión bien pensada pero irrealizable. Por el contrario, se trata de un proyecto para las instituciones, las relaciones sociales y las conductas. El panóptico responde al deseo de que lo visto se conjugue con lo dicho sin ofrecer resistencias o disidencias posibles; es, en pocas palabras, todo un programa político. De alguna manera, los programas dan lugar a una mirada que habla y un discurso que hace ver: tal es su forma de producir realidad, su verdad..., aunque también es aquello que desde el comienzo los torna inestables, inacabados y desviados.

Señalé que las positividades que corresponden a la arqueología de la política deben buscarse en los núcleos inestables de poder-saber; ahora podría añadir que los programas surgen justo en la fisura entre lo que se dice y lo que se ve:

¿El hombre que podemos ver en un manicomio es el mismo que podemos enunciar como loco? [...] Muchos de los que están en el manicomio no deberían estar en él, pero también muchos que no están deberían estarlo: la psiquiatría del siglo XIX se elaboró a partir de esta constatación que lejos de crear un concepto unívoco y determinado de locura, la "problematiza". (Deleuze 2008, pp. 92-93)

En el punto de partida de las positividades arqueológico-políticas siempre hay un problema por definir mediante las prácticas discursivas. Foucault denomina a esas prácticas "formas de problematización"; esto 
es, el punto a partir del cual un dominio o una situación concreta, que hasta entonces podía resultar irrelevante o pasar desapercibida, se transforma en un problema que necesita abordarse.

Las formas de problematización ocupan un lugar primordial en el análisis arqueológico: "La dimensión arqueológica del análisis permite analizar las formas mismas de la problematización; la dimensión genealógica, su formación a partir de las prácticas y de sus modificaciones" (Foucault 1984, pp. 17-18). El análisis de las formas de problematización no se detiene en la pura dispersión de las prácticas, sino que busca abordarlas en sus posibles articulaciones, yuxtaposiciones y regularidades. Para una arqueología de la política, es aquí donde las problematizaciones se convierten en programaciones:

Se trata de hacer el análisis de un "régimen de prácticas" — las cuales se consideran el lugar de unión entre lo que se dice y lo que se hace, las reglas que se imponen y las razones que se dan de los proyectos y las evidencias-. Analizar los "regímenes de prácticas" es analizar las programaciones de conducta, que tienen a la vez unos efectos de prescripción en relación con lo que se está por hacer (efectos de "jurisdicción") y unos efectos de codificación en relación con lo que se está por saber (efectos de "veridicción"). (Foucault 1994d, p. 22)

Ahora bien, ¿cómo analizar los efectos de veridicción de las programaciones desde una perspectiva arqueológico-política? No es posible concebir los programas como positividades arqueológicas sin hacer todo un esfuerzo metodológico, una conversión de la mirada, que nos ahorre pensar en modelos susceptibles de aplicarse en forma completa y exhaustiva. En efecto, cuando hablamos de programaciones como el panóptico, no pensamos en proyectos que actúan de manera unilateral, de arriba hacia abajo, y que moldean la realidad a su imagen y semejanza. Al contrario, porque surgen de la fisura insalvable entre lo que se ve y lo que se dice, porque son el intento de cerrar algo que desde siempre permanece abierto, los programas están sujetos a constantes modificaciones y desviaciones. Ello no implica que éstos sean una suerte de ideal truncado ante los obstáculos y las contingencias que opone la realidad. La historia de las ideas podría hacernos concebir los programas como aspiraciones que fracasan y que, por lo tanto, deben corregirse sobre la marcha. Si así fuera, deberíamos decir entonces que los programas son elementos que poseen diferentes grados de aplicación, yendo desde la linealidad absoluta hasta las desviaciones que reducen su identidad al mínimo. La perspectiva arqueológico-política 
evita esta clase de "deductivismo". Los programas no son ideas que se aplican de una manera más o menos lineal, más o menos desviada; para Foucault, "son fragmentos de realidad que inducen unos efectos de realidad tan específicos como los de la división entre lo verdadero y lo falso en la manera como los hombres se 'dirigen', se 'gobiernan', se 'conducen' a sí mismos y a los demás” (Foucault 1994d, p. 29). Las programaciones producen determinados efectos de veridicción, pero no en términos absolutos, sino como fragmentos de realidad. Esto significa que contribuyen a hacer la realidad un tanto más gobernable, sin llegar nunca a determinarla en su totalidad.

Sin duda, ni las sociedades ni las instituciones y ni siquiera los hombres se comportan como se espera en las programaciones. Sin embargo, ello no implica que sean elementos inocuos o inefectivos. Los programas intervienen en nuestras formas de apreciar y valorar las cosas, hacen que las consideremos un problema o una solución, un objeto de intervención o una finalidad de las prácticas. No hay prisión que funcione o que haya funcionado alguna vez como lo soñó Bentham; antes bien, las prisiones se parecen al infierno en comparación con ese sueño:

Pero, precisamente, si han aparecido como tales, si los delincuentes han sido vistos como incorregibles, si se ha perfilado a los ojos de la opinión e incluso de la "justicia" una raza de "criminales", y si la resistencia de los prisioneros y el destino del reincidente han tomado la forma que conocemos, es porque este tipo de programación no fue sólo una utopía en la cabeza de algunos hacedores de proyectos. (Foucault 1994d, p. 29)

\section{Del archivo a las racionalidades de gobierno}

La arqueología de la política puede llevarnos hasta los discursos de personajes a veces oscuros, poco conocidos u olvidados. Esto no es casual, pero tampoco tiene que ver con un mero afán de erudición histórica; por el contrario, a través de los proyectos y las programaciones de esos personajes aprendemos algo sobre los procesos políticos y sociales que intervinieron en la conformación de nuestro presente. Lo que se pone en juego no es un conocimiento científico; es más bien un conjunto de saberes ingenuos, poco elaborados y difíciles de sistematizar en teorías generales. ${ }^{6}$ Dicho en términos arqueológicos, el desafío consiste en

${ }^{6}$ Precisamente en este punto la arqueología de la política se entrecruza con el método genealógico que Foucault desarrolló a principios de la década de 1970. En ambos casos, se trata de reactivar las fracturas y los conflictos que encubren las teorías generales. La diferencia — como también los posibles puntos de articulación- 
analizar los procesos de "rarefacción" de las prácticas discursivas sin remitirse a la disciplina desde la cual se habla, a las supuestas intenciones del autor, a la mentalidad de la época o a cualquier otra totalidad previamente establecida (Foucault 1969, Foucault 1971). Para el caso que aquí interesa, se trata de recuperar unos saberes que no pueden reducirse con facilidad a disciplinas o áreas específicas de conocimiento, pues combinan diferentes perspectivas sociales, económicas, filosóficas e históricas. Tal es el caso de las programaciones descritas con el método arqueológico-político. En esos saberes descalificados con frecuencia por la teoría y la filosofía política vemos dibujarse las memorias discontinuas y contradictorias de nuestro presente; aquellas que, a la manera de los fragmentos centellantes de Nietzsche, se cristalizan en las instituciones, en los comportamientos de hombres y mujeres, así como también en nuestros marcos de percepción y estimación de las cosas.

Pero hay que avanzar siempre con precaución, sobre todo cuando se trabaja con diferentes proyectos y programaciones. Al seguir la forma de estas positividades, la arqueología de la política adivina el impulso de una sociedad posible o futura. Ahora bien, ¿cómo puede un saber mostrarnos algo semejante? ¿Cómo hacer inteligible la sociedad, el Estado o la economía sin las unificaciones y las sistematizaciones de las teorías generales? Los programas no deben analizarse en los términos de la historia convencional, esto es, como "marcas que, una vez descifradas, pueden liberar, por medio de una especie de memoria que atraviesa los tiempos, significaciones, pensamientos, deseos, fantasmas sepultados" (Foucault 1969, p. 161). No se trata de trabajar con documentos supuestamente sometidos al silencio para tratar de descifrar aquello que los hombres habrían querido hacer y decir en realidad, sino de describir las posibles regularidades en las cuales ingresan las prácticas discursivas. Foucault sostenía que la arqueología del saber trabaja con el "archivo" como sistema general que rige la formación y la transformación de los enunciados; la ley de lo que puede y no puede decirse en determinados momentos y lugares (Foucault 1969, pp. 170-171). Pues bien, la arqueología de la política tiene en este punto un equivalente al archivo.

Así lo sugiere Foucault cuando señala que los programas no deben entenderse como elementos aislados o como producto de la imaginación de algunos pensadores, sino como aquello que nos permite en-

está en los alcances de cada herramienta metodológica: "la arqueología sería el método propio del análisis de las discursividades locales, y la genealogía, la táctica que, a partir de esas discursividades locales así descritas, ponen en juego los saberes liberados del sometimiento que se desprenden de ellas" (Foucault 2008, p. 24).

Revista de Filosofía Diánoia, vol. 65, no. 84 (mayo-octubre de 2020) e-ISSN: 1870-4913 • DOI: https://doi.org/10.22201/iifs.18704913e.2020.84.1603 
trever una "racionalidad" más amplia. Esta racionalidad "no es simplemente un principio teórico y de técnicas científicas, no produce sólo unas formas de conocimiento o unos tipos de pensamiento, sino que está ligada por vínculos complejos y circulares a unas formas de poder" (Foucault 1994d, p. 16). A los fines de una arqueología de la política, es necesario no confundir el análisis de las racionalidades con la crítica a la "racionalización" como proceso general de las sociedades modernas. En numerosas ocasiones, Foucault subraya esa importante precaución: "Sin duda es prudente no tratar a la racionalización de la sociedad o de la cultura como si fuese un todo, sino analizar ese proceso en diferentes dominios - cada uno de ellos enraizado en una experiencia fundamental: locura, enfermedad, muerte, crimen, sexualidad, etc.--" (Foucault 1994e, p. 135). ${ }^{7}$ En lugar de considerar la racionalización como una tendencia universal y totalizante, capaz de avanzar sobre la sociedad sin hacer distinción alguna, la arqueología de la política analiza las formas de racionalidad que aparecen en diferentes dominios de prácticas. ¿Qué racionalidad surgió de las prácticas destinadas a morigerar el índice de delitos en algunas de las ciudades europeas más populosas del siglo XVIII? ¿Cómo y hasta qué punto la nueva racionalidad fue dando un orden a las prácticas mismas? ¿Cuáles fueron los problemas que en tal caso se visibilizaron e intentaron solucionar? ¿Con qué objetivos y qué métodos? ¿Qué instancia de veridicción resultó de todo ello? Se realizan cálculos, se desarrollan técnicas y se estiman posibles resultados en función de una situación concreta; esto es, sin apelar a ninguna facultad o sabiduría que trascienda las prácticas y sus posibles formas de regularidad.

$\mathrm{Si}$ bien la racionalidad de gobierno se aborda siempre desde una perspectiva "minimalista", desprovista de cualquier tipo de universalismo, el trabajo arqueológico-político no tiene que limitarse necesariamente al análisis de alguna institución en particular. Antes bien, "La cuestión consiste en conocer cómo están racionalizadas las relaciones de poder. Plantearse esta cuestión es la única manera de evitar que otras instituciones, con los mismos objetivos y los mismos efectos, tomen su lugar" (Foucault 1994e, p. 161). Emergidas desde la superficie de las prácticas, las racionalidades de gobierno pueden superponerse y entrecruzarse hasta el punto de trazar un modo más o menos general

\footnotetext{
${ }^{7}$ Foucault se refiere en este punto a la Escuela de Fráncfort en general, aunque también habría que considerar más puntualmente sus diferencias con Jürgen Habermas en torno a las relaciones entre "la" razón y las diversas formas de racionalidad. Acerca del debate entre Foucault y Habermas, véase, entre otros, Dean 1994.
} 
de percibir y de resolver problemas, de realizar cálculos y aplicar procedimientos para éste u otro campo de prácticas. En gran medida, su amplitud depende del éxito o de la capacidad que demuestren para zanjar fisuras y divergencias. ${ }^{8} \mathrm{Si}$ el modelo o programa de la "ciudad apestada" resultó tan eficaz para gobernar las situaciones de peste, ¿cómo no utilizarlo, con las modificaciones y las adaptaciones correspondientes, para el gobierno de los locos? Si el panoptismo permitió aumentar el poder de vigilancia en las prisiones, ¿̇por qué no aplicarlo para aumentar la producción en las fábricas, curar a los enfermos o instruir a los escolares? Sin necesidad de una planificación stricto sensu, sin que nadie lo haya previsto en todo detalle y hasta sus últimas consecuencias, se produce una dirección predominante en la forma de organizar las instituciones, diagramar los espacios y regular las conductas.

$\mathrm{El}$ análisis de las racionalidades de gobierno transita de forma continua entre la microfísica del poder y una "macrofísica" que se proyecta en la escala de las sociedades y las poblaciones. En otras palabras, no sólo se trata de analizar una técnica específica de poder como la que interviene al enmendar a los delincuentes, curar a los enfermos o adiestrar a los niños, sino también una política económica o sanitaria, un proyecto de reforma urbana o cualquier otro programa dirigido al cuerpo social entero. ${ }^{9}$ Más allá de las cuestiones de escala, el análisis se enfoca siempre en las prácticas discursivas y en las maneras de hacer antes que en las necesidades del Estado, la sociedad o cualquier otra entidad sobredeterminante. No habría que ver aquí el a priori de las prácticas; por el contrario, habría que ver unas "entidades cuya propia inteligibilidad depende de modos de codificar y articular lo real que han debido inventarse. Esos objetos de gobierno tienen precondiciones materiales y conceptuales particulares que dependen de conocimientos,

${ }^{8}$ Según Pablo de Marinis Cúneo: "Las racionalidades desarrollan en el trascurso de su despliegue una coherencia práctica, pero no la tienen desde el principio mismo de su aplicación. [...] unas racionalidades específicas se constituyen a partir del éxito de determinadas modalidades de resolver problemas de la práctica social (y consecuentemente a partir del fracaso de otras); ellas, luego, se vuelven ejemplares y son imitadas y aplicadas por analogía" (de Marinis Cúneo 1999, p. 88).

${ }^{9}$ En tal sentido, el método arqueológico-político bien puede servir como punto de apoyo para los cambios de escala sobre los cuales habla Foucault en Naissance de la biopolitique: "es posible admitir que el análisis de los micropoderes o los procedimientos de la gubernamentalidad no se limita por definición a un área específica que se definiría por un sector de la escala, sino que debería considerarse un simple punto de vista, un método de descifrado que puede ser válido para toda la escala, sea cual sea su magnitud" (Foucault 2004, p. 192). 
técnicas y competencias específicas para existir y funcionar" (Gordon 1987, p. 298).

Así llegamos al último apartado de este artículo, que consiste en explorar algunas de las programaciones históricas mediante las cuales el Estado, la sociedad y la economía adquieren no sólo una racionalidad específica, sino que se hacen inteligibles como objetos de debate para la política.

\section{Una grilla de inteligibilidad para la política}

De acuerdo con mi hipótesis de lectura, se puede encontrar un trabajo arqueológico-político en la base de las categorías y análisis que Foucault elabora durante la década de 1970. Dicho trabajo no excluye otras herramientas metodológicas; en todo caso, es uno de los tantos puntos que sirven de apoyo a sus investigaciones sobre la gubernamentalidad. A través de esas investigaciones, Foucault esboza una "grilla de inteligibilidad" para la política sirviéndose de prácticas y saberes gubernamentales. Se trata, como ya vimos, de una elección metodológica opuesta al uso de los universales: "en lugar de partir de los universales para deducir fenómenos concretos, o partir más bien de los universales como grilla de inteligibilidad obligatoria para una serie de prácticas concretas, preferiría comenzar por estas prácticas concretas y, de algún modo, pasar los universales por la grilla de las mismas" (Foucault 2004, pp. 4-5). Así, desde las prácticas concretas, es decir, desde sus articulaciones, sus apoyos y sus formas de regularidad, podemos interrogar cómo lo estatal, lo social y lo económico se tornan realidades inteligibles y problematizables.

A esta grilla de inteligibilidad contribuye el análisis de la razón de Estado emergida entre los siglos XVI y XVII, el liberalismo de los siglos XVIII a XIX y el neoliberalismo del siglo XX. ${ }^{10} \mathrm{Si}$ retomamos los análisis de Foucault, podríamos ver que el punto de partida está casi siempre en los saberes de un conjunto de intelectuales y funcionarios que hasta el día de hoy pueden resultar en gran parte ignotos. A continuación recorreremos la trama de esos saberes, no con pretensiones de exhaustividad ni de profundizar lo ya analizado por Foucault, sino con

${ }^{10}$ Aquí sigo el hilo de las tres racionalidades de gobierno que Foucault analiza en los cursos Sécurité, territoire et population y Naissence de la biopolitique, aunque igualmente se podrían seguir, como una línea adicional que a veces se entrecruza con la primera, los contradiscursos de la lucha de razas y su transcripción en los programas de orientación médico-sanitaria en el curso Il faut défendre la société (Foucault 2008 [1976]).

Revista de Filosofía Diánoia, vol. 65, no. 84 (mayo-octubre de 2020) e-ISSN: 1870-4913 • DOI: https://doi.org/10.22201/iifs.18704913e.2020.84.1603 
el simple objetivo de mostrar un posible campo de investigación para el desarrollo del método arqueológico-político.

Durante los siglos XVI y XVII, tanto en los márgenes de los principios cristianos de gobierno como también del famoso discurso del Príncipe de Maquiavelo, aparece un campo de saberes basados en la supuesta naturaleza o disposición de las cosas que se deben gobernar. Son saberes políticos más relacionados con las variables del territorio, las conductas y las relaciones entre los hombres que con los preceptos de la razón divina o la serie de virtudes necesarias para adquirir y conservar el poder. Según Foucault, esos saberes se definen en relación con:

La idea de que no puede haber gobierno si quienes gobiernan no ajustan sus acciones, sus elecciones, sus decisiones, a un conjunto de conocimientos verdaderos, de principios racionalmente fundados o de conocimientos exactos que no sólo dependen de la sabiduría en general del príncipe o de la razón sin más, sino de una estructura racional que es propia de un dominio de objetos posibles. (Foucault 2012, p. 14)

Si bien estos saberes recibieron el nombre de "ciencia de la política" o "ciencia del gobierno", no era exactamente unos conocimientos científicos lo que venían a poner en juego. Lo que desplegaban era más bien un "arte" específico de gobierno; un arte que, por así decirlo, tenía su propia ratio.

$\mathrm{El}$ arte de gobierno se refiere a una manera de pensar, razonar y calcular el ejercicio del poder. Su forma no tiene que ver con los métodos y los procedimientos científicos, sino con aquello que se debe gobernar o dirigir, como si fuese en principio una cuestión de tacto, de saber disponer bien las cosas, antes que de obtener un conocimiento sistematizado sobre las mismas. Ello no implica que se trate de saberes ambiguos e inconexos; por el contrario, el arte de gobierno tiene siempre una ratio que le da un orden y una coherencia propia. Entre los siglos XVI y XVII, esa ratio residía precisamente en el Estado. Fue en torno a éste que se ordenaron y racionalizaron las más diversas prácticas de gobierno, desde la pedagogía y la salud hasta la diplomacia y las tácticas militares. De ahí el uso de la expresión "razón de Estado", que no se refiere tanto a las leyes intrínsecas del poder estatal como a una manera de pensar, calcular y programar las prácticas de gobierno. Para muchos administradores y consejeros de la época, en especial para los mercantilistas y cameralistas del siglo XVII, la razón de Estado era un principio orientador o, más todavía, un marco de inteligibilidad de las prácticas: "el Estado, en este pensamiento político que buscaba la racionalidad de 
un arte de gobernar, fue ante todo un principio de inteligibilidad de lo real. Fue cierta manera de pensar lo que eran en su naturaleza propia y sus vínculos y relaciones una serie de elementos, una serie de instituciones ya dadas" (Foucault 2006, p. 328). La diferencia es sutil, aunque sin duda importante. En el límite de los saberes políticos emergidos durante los siglos XVI y XVII, el Estado no aparece como algo capaz de desarrollarse por sí mismo e imponerse de manera automática sobre los individuos, sino como un proyecto gubernamental, vale decir, un marco para descifrar lo que es y lo que debe ser: "El Estado es lo que debe haber al cabo de la operación de racionalización del arte de gobernar. [...] El Estado es, por lo tanto, un principio de inteligibilidad de lo que es, pero también de lo que debe ser" (Foucault 2006, p. 329). El Estado como forma de ordenar las prácticas y como objetivo de las prácticas; en otras palabras, el Estado como programa.

Sin embargo, las programaciones estatales tienen sus fisuras, desviaciones y hasta momentos de trasformación completa. En efecto, si las prácticas de gobierno se deben ajustar al conocimiento preciso de los procesos y dominios que hacen al Estado, habrá entonces un punto en el que ya no será necesario gobernar demasiado, puesto que la verdad se manifestará e impondrá por sí misma:

[D]ebe llegar un momento, una especie de punto utópico en la historia, donde el imperio de la verdad pueda hacer reinar su orden sin que las decisiones de una autoridad, sin que las elecciones de una administración tengan que intervenir de otra manera que como formulación evidente a los ojos de todo el mundo de lo que hay que hacer. (Foucault 2012, p. 15)

Surge así la posibilidad de gobernar conforme a la "evidencia de las cosas"; o también, y si se quiere, la idea de un gobierno continuamente ajustado a la leyes de la naturaleza. A este programa gubernamental basado en la búsqueda de una superposición completa entre las reglas de la evidencia y las acciones de gobierno, Foucault lo denomina "liberalismo".

Desde la perspectiva arqueológico-política, el liberalismo puede entenderse en parte como una programación de sociedad. Basta consultar algunos tratados de los siglos XVIII y XIX, desde la fisiocracia y la escuela escocesa hasta el empirismo inglés, el utilitarismo y la escuela neoclásica, para que veamos centellar un orden de cosas distinto al orden de la razón de Estado. Más que intervenir en los individuos y las riquezas de un territorio en pos de la grandeza y esplendor del Estado, se entiende que el mejor gobierno es el capaz de autolimitarse ante una 
realidad dotada de sus propias leyes y dinámicas. Esa realidad es la "sociedad civil" o —según los términos del liberalismo económico de fines del siglo XVIII y principios del siglo XIX - la "sociedad de mercado". ${ }^{11}$ La cuestión consiste en hacer de la sociedad un dominio de referencia para las prácticas de gobierno, convirtiéndola en la ratio que permite calcular cómo y hasta qué punto gobernar. En función del desarrollo de una arqueología de la política, interesa centrarse en aquellas programaciones que buscan hacer de la sociedad un mercado indefinido y del mercado una forma de sociabilidad. Son programaciones basadas en la utopía de un orden transparente para sí mismo, constituido por relaciones impersonales e imparciales, sin necesidad de subordinaciones ni relaciones de fuerza. ${ }^{12}$ No es que a partir de aquí pueda abrirse realmente una era de paz y de armonía social. Lo que estas programaciones abren es más bien una forma de reflexión, de análisis y de cálculo político que puede articularse y que de hecho se ha articulado históricamente con otras racionalidades y programaciones gubernamentales. ${ }^{13}$

Así pues, el análisis arqueológico-político nos permite entender el liberalismo desde una perspectiva diferente, no tanto como un simple

${ }^{11}$ A diferencia de lo que podríamos presuponer, la idea de naturaleza no funciona en la racionalidad liberal como una realidad eterna o divina, imposible de ser intervenida por parte del gobierno; al contrario, la naturaleza es un correlato de las mismas intervenciones gubernamentales, un campo que se constituye como efecto de éstas y que, a su vez, les sirve como principio de regulación interna. Desde mediados del siglo XVIII, el orden natural al cual los gobiernos deben ajustarse recibe el nombre de "sociedad civil": "En el centro de la reflexión liberal —señala Tomas Lemke- se encuentra una naturaleza desconocida que hasta entonces es el resultado histórico de las transformadas condiciones de producción y de vida: la 'segunda' naturaleza de la sociedad civil en desarrollo" (Lemke 2017, p. 62). Lo que se abre a partir de allí es una serie de posibilidades de intervención que, en contraste con la razón de Estado, no se expresan en prescripciones o reglamentaciones directas, sino en mecanismos de incitación y estimulación: laissez-faire, laissez-passer.

${ }^{12}$ Como señala Pierre Rosanvallon, el proyecto de la sociedad de mercado responde a la aspiración de "desdramatizar" las relaciones entre los individuos, desactivando sobre todo el potencial de violencia que éstas conllevan: "la idea de mercado cumple con cierta idea de autonomía de los individuos al despersonalizar la relación social. El mercado representa el arquetipo de un sistema de organización antijerárquica, de un modelo de toma de decisión en el cual no interviene ninguna intencionalidad" (Rosanvallon 2006, p. 9).

${ }^{13}$ Un buen ejemplo se encuentra en el libro La invención de lo social de Jacques Donzelot, donde se muestra la manera en que el liberalismo se articuló con otras racionalidades de gobierno, en especial con las racionalidades securitarias que se basaban en la filosofía de la solidaridad y que estaban muy vigentes en la coyuntura política y social de la Francia de fines del siglo XIX (Donzelot 2007). 
conjunto de ideas económicas y jurídicas, sino como una forma de programar los vínculos sociales en profundidad. Lo mismo vale para el caso del neoliberalismo, que no siempre niega toda proyección u horizonte social en favor del desorden y la heterogeneidad. ${ }^{14}$ Cuando se retoman los tratados que analiza Foucault, vemos que también aquí parece proyectarse una forma de ordenamiento social:

[L]a intervención gubernamental —y esto, los neoliberales lo dijeron siempre- no es menos densa, menos frecuente, menos activa, menos continua que en otro sistema. [...] El gobierno debe intervenir sobre la sociedad misma en su trama y su espesor. En el fondo - y es aquí donde su intervención le permitirá alcanzar su objetivo, es decir, la constitución de un regulador general del mercado sobre la sociedad - tiene que intervenir para que los mecanismos competitivos, a cada instante y en cada punto del espesor social, puedan cumplir con su papel de reguladores. (Foucault 2004, p. 151) $)^{15}$

A pesar de las similitudes aparentes, hay importantes diferencias entre el liberalismo y el neoliberalismo. La primera puede advertirse en el nivel de las programaciones de la sociedad. Mientras que el liberalismo programa una sociedad en la cual el libre intercambio y la circulación de mercancías constituyen un orden completamente trasparente para sí mismo, el neoliberalismo programa una sociedad transida por la lógica de la competencia entre empresas:

Estos mecanismos deben adquirir la mayor superficie y espesor posibles, ocupando también el mayor volumen posible de la sociedad. Es decir que se procura obtener no una sociedad sometida al efecto de la mercancía,

${ }^{14}$ Tal es la tesis que plantea Geoffroy de Lagasnerie en su libro La última lección de Michel Foucault. Sobre el neoliberalismo, la teoría y la política (De Lagasnerie 2015). Al menos desde la perspectiva de este artículo, es una tesis que la arqueología de la política debería poner en tela de juicio, sobre todo porque se sirve de los mismos análisis de Foucault para presentar el neoliberalismo como la superación definitiva de otras racionalidades de gobierno.

${ }^{15}$ Cabe aclarar que Foucault extrae estas conclusiones de un conjunto de economistas, sociólogos y juristas que han quedado a la sombra de los neoliberales más conocidos, en especial de Hayek y Friedman. Son esos nombres que aparecen a lo largo del curso Naissance de la biopolitique, como Eucken, Rüstow, Röpke y MüllerArmack, entre otros, y cuyos escritos merecen sin duda un análisis arqueológicopolítico. Así, veríamos emerger un neoliberalismo no sólo poco conocido para nuestra actualidad, sino también poco criticado en cuanto a su dimensión programática y sus posibilidades de racionalización gubernamental. 
sino una sociedad sujeta a la dinámica competitiva. No una sociedad de supermercado: una sociedad de la empresa. (Foucault 2004, p. 152)

La diferencia que señala Foucault no es menor; en el límite, deja entrever una racionalidad de gobierno que no termina de asimilarse por completo ni con el liberalismo ni con ninguna otra racionalidad vigente.

El liberalismo parte de una premisa básica: no hay que "gobernar demasiado" - es decir, no hay que intervenir donde las leyes de mercado se manifiestan en toda su evidencia-. Sin embargo, durante gran parte del siglo XIX y hasta bien entrado el siglo XX varios gobiernos se vieron empujados a reformular esa premisa al intervenir directamente en los mercados para prevenir algunos de sus efectos más destructivos sobre las relaciones sociales. ${ }^{16}$ El neoliberalismo nace en gran parte de esa insalvable fisura, buscando unir lo que el liberalismo mantenía aún separado. Ya no se trata de dejar el espacio suficiente para la circulación y los intercambios mercantiles, sino de proyectar hacia las propias prácticas del gobierno el principio de la competencia de mercado. Según Foucault, esto implica algo más que liberalizar los mercados e intervenir sólo cuándo no funcionen como se esperaba. Lo que se busca es la multiplicación y la diseminación de las empresas a través de todo el tejido social, de modo tal que sean estas últimas, y no simplemente los mercaderes o comerciantes individuales, las que entren en competencia. En el marco de la racionalidad neoliberal de gobierno, la empresa aparece como el punto donde la competencia se hace visible y a la vez enunciable; es lo que permite traducir cada conducta, idea o iniciativa en una serie de recursos que se ofrecen al mercado. ${ }^{17}$

${ }^{16}$ El economista austriaco Karl Polanyi ilustró este punto con toda claridad a mediados del siglo xx. De hecho, sus críticas al principio liberal del laissez-faire no sólo fueron compartidas por varios economistas keynesianos, sino también por Hayek y otros neoliberales, aunque con consecuencias y efectos sumamente distintos (Polanyi 2001).

${ }^{17} \mathrm{El}$ programa de la sociedad de empresa ha sido llevado al extremo por Gary Becker y otros economistas de la Escuela de Chicago, cuyos análisis procuran extender la empresa y los criterios empresariales — como la inversión, la capitalización y la estimación de riesgos- a un conjunto de ámbitos no estrictamente económicos: "La generalización de la forma económica del mercado, incluso más allá de los intercambios monetarios, funciona en el neoliberalismo norteamericano como un principio de inteligibilidad, un principio de desciframiento de las relaciones sociales y de los comportamientos individuales. [...] Gracias a este esquema de análisis, esta grilla de inteligibilidad podrá revelarse en procesos no económicos, en relaciones no económicas, en comportamientos no económicos, un cierto número 
La descripción de las particularidades y diferencias entre la razón de Estado, la racionalidad liberal y el neoliberalismo excede indudablemente el alcance de este trabajo. ${ }^{18}$ Para una arqueología de la política, la cuestión verdaderamente importante es que los saberes desplegados en forma de programas permiten hacer inteligible la realidad o, mejor dicho, las racionalidades fragmentarias y a veces contradictorias que atraviesan a los objetos, los conceptos y las elecciones estratégicas presentes en los debates políticos. En efecto, las racionalidades de gobierno no deben entenderse como compartimentos estancos y sucesivos en el tiempo, sino como maneras de decir y hacer que se encabalgan, se apoyan en forma mutua o bien se enfrentan entre sí. No otro es el punto donde, como señala Foucault, nace la política: “¿Qué es la política, finalmente, si no el juego de las diferentes artes de gobierno con sus diferentes ajustes y debates que suscitan? Es ahí que nace la política" (Foucault 2004, p. 317). Si las relaciones entre el Estado, la sociedad y la economía han sido desde los últimos siglos objeto de un debate político inacabable, hay que advertir entonces que las posibles respuestas a ese debate están sujetas - y al mismo tiempo pueden dar lugar- a racionalidades gubernamentales muy distintas. De hecho, es ahí donde "lo estatal", "lo económico" y "lo social" aparecen como realidades en disputa, donde se tornan inteligibles e incluso se reconfiguran en sus relaciones mismas.

\section{Conclusiones}

Comencé este artículo señalando el rechazo de Foucault a los universales; pues bien, ahora podría decir que el reverso de ese rechazo está en la demarcación constante de la diferencia y la singularidad que hace a nuestro presente. A ese trabajo de demarcación, que se sirve tanto del método genealógico como arqueológico, Foucault lo denomina "ontología del presente". No se trata de aprehender la esencia constitutiva de nuestro presente o de descubrir las leyes universales que rigen su desarrollo, sino más bien de hacer ver lo que éste tiene de accidental o contingente:

de relaciones inteligibles que no habría aparecido de ese modo —una especie de análisis economicista de lo no económico- (Foucault 2004, p. 249).

${ }^{18}$ Se encontrará un estudio pormenorizado de estas cuestiones en Castro-Gómez 2010. Ofrezco un análisis de las diferencias entre la racionalidad liberal y neoliberal de gobierno en Méndez 2014, Méndez 2017a y Méndez 2017b. Para un análisis sobre la racionalidad neoliberal de gobierno, véase Laval y Dardot 2013. 
Esta crítica no es trascendental, y no pretende hacer posible una metafísica: es genealógica en su finalidad y arqueológica en su método. Arqueológica —y no trascendental— en el sentido de que no buscará extraer las estructuras universales de toda posible cognición o acción moral, sino que tratará los discursos que articulan lo que pensamos, decimos y hacemos como acontecimientos históricos. Y esta crítica será genealógica en el sentido de que no deducirá de la forma de lo que somos lo que no podemos hacer o saber, sino que extraerá de la contingencia que nos ha hecho ser lo que somos la posibilidad de ya no ser, hacer o pensar lo que somos, hacemos y pensamos. (Foucault 1994f, p. 574)

Las líneas de investigación están abiertas y deben continuarse a través de innumerables trabajos y puestas a prueba. Para quienes tengan interés en seguir las huellas metodológicas de Foucault, la arqueología de la política brinda un criterio posible de desciframiento y diferenciación en vistas al enriquecimiento del análisis político. Hay ciertos momentos y lugares en que las coordenadas de ese análisis alcanzan un límite difícil de franquear, como sucede por ejemplo cuando se convierte "lo estatal", "lo social" y "lo económico" en entidades universales y se deduce a partir de éstas una serie de clasificaciones políticas aparentemente excluyentes, yendo desde la izquierda hasta la derecha o desde el progresismo hasta el conservadurismo, entre otras tantas dicotomías posibles. ¿Qué decir entonces cuando los defensores del mercado llaman a fortalecer la incidencia del Estado en la sociedad, cuando ciertos funcionarios del gobierno considerados neoliberales hablan de reconstruir los lazos sociales o cuando algunos pensadores autodenominados de izquierda proponen desregular la economía ${ }^{19}$ ¿Se trata de un mero absurdo, un artilugio mal elaborado o hay quizá un programa que articula y da racionalidad a todo ello? Allí donde nuestros marcos de desciframiento habituales encuentran absurdos o propuestas infundadas, el trabajo arqueológico-político nos permite dilucidar una racionalidad

${ }^{19}$ Sobre este último punto, me remito al análisis de Christian Laval y Pierre Dardot acerca de la "nueva izquierda" europea y en particular de la "Tercera vía" inglesa surgidas en la década de 1990. Si bien esas alternativas se caracterizan por tomar una distancia crítica ante el liberalismo del laissez-faire, no escapan a la racionalidad neoliberal de gobierno: "aunque la izquierda moderna denuncie esa 'ideología de la jungla' para desmarcarse de la derecha, acepta, asume, reproduce una forma de pensamiento, una manera de plantear problemas y, en consecuencia, un sistema de respuestas que constituye una racionalidad envolvente - es decir, un tipo de discurso normativo con el que la realidad entera se torna inteligible y en virtud del cual se prescriben, como si 'cayeran por su propio peso', cierto número de políticas determinadas-" (Laval y Dardot 2013, p. 326). 
de gobierno operante o en vías de formación. El aporte no es nada menor. Lo que posibilita son nuevas herramientas para el análisis político o, mejor aún, otra manera de hacer ver y decir la política que parte de las mismas prácticas discursivas de gobernantes y gobernados.

\section{Referencias bibliográficas}

Castro, Eduardo, 2016, Lecturas foucaultianas. Una historia conceptual de la biopolítica, Universidad Pedagógica Nacional, Buenos Aires.

Castro-Gómez, Santiago, 2010, Historia de la gubernamentalidad. Razón de Estado, liberalismo y neoliberalismo en Michel Foucault, Siglo del Hombre, Bogotá.

De Marinis Cúneo, Pablo, 1999, “Gobierno, gubernamentalidad, Foucault y los anglofoucaultianos ( $\mathrm{O}$ un ensayo sobre la racionalidad política del neoliberalismo)", en F. García Selgas y R. Ramos Torre (comps.), Globalización, riesgo y reflexividad. Tres temas de la teoría social contemporánea, Centro de Investigaciones Sociológicas, Madrid, pp. 73-101.

Dean, Mitchel, 1994, Critical and Effective Histories. Foucault's Methods and Historical Sociology, Routledge, Nueva York, $<$ https://doi. org/10.4324/97802 03414217>.

Deleuze, Gilles, 2008, Foucault, pról. Miguel Morey, trad. José Vázquez Pérez, Paidós, Buenos Aires.

Donzelot, Jacques, 2007, La invención de lo social. Ensayo sobre la declinación de las pasiones políticas, trad. Heber Cardoso, Nueva Visión, Buenos Aires.

Dreyfus, Hubert L. y Paul Rabinow, 2017, Michel Foucault: más allá del estructuralismo y la hermenéutica, trad. Rogelio C. Paredes, Monte Hermoso, Buenos Aires.

Foucault, Michel, 1963, Naissance de la clinique. Une archéologie du regard médical, Presses Universitaires de France, París.

Foucault, Michel, 1966, Les mots et les choses. Une archéologie des sciences humaines, Gallimard, París.

Foucault, Michel, 1969, L'archéologie du savoir, Gallimard (Biblioteca des sciences humaines), París.

Foucault, Michel, 1971, L'ordre du discours: leçon inaugurale au Collège de France prononcée le 2 décembre 1970, Gallimard, París.

Foucault, Michel, 1976, La volonté de savoir. Histoire de la sexualité I, Gallimard, París.

Foucault, Michel, 1984, L'usage des plaisirs. Histoire de la sexualité II, Gallimard, París.

Foucault, Michel, 1994a, "L'œil du pouvoir", en Dits et écrits III (1976-1979), Gallimard, París, pp. 190-207.

Foucault, Michel, 1994b, "Les rapports de pouvoir passent à l'intérieur des corps", en Dits et écrits III (1976-1979), Gallimard, París, pp. 228-236. 
Foucault, Michel, 1994c, "La philosophie analytique de la politique", en Dits et écrits III (1976-1979), Gallimard, París, pp. 534-550.

Foucault, Michel, 1994d, "La pussière et le nuge", en Dits et écrits IV (19801988), Gallimard, París, pp. 12-37.

Foucault, Michel, 1994e, “'Ommes et singulatim': vers une critique de la raison politique”, en Dits et écrits IV (1980-1988), Gallimard, París, pp. 134-161.

Foucault, Michel, 1994f, "Qu'est-ce que les Lumières?", en Dits et écrits IV (1980-1988), Gallimard, París, pp. 562-578

Foucault, Michel, 2004, Naissance de la biopolitique. Cours au Collège de France (1978-1979), Seuil/Gallimard, París.

Foucault, Michel, 2006, Seguridad, territorio, población. Curso en el Collège de France (1977-1978), trad. Horacio Pons, Fondo de Cultura Económica, Buenos Aires.

Foucault, Michel, 2008, Defender la sociedad. Curso en el Collège de France (1975-1976), trad. Horacio Pons, Fondo de Cultura Económica, Buenos Aires.

Foucault, Michel, 2012, De gouvernement des vivants. Cours au Collège de France (1979-1980), Seuil/Gallimard, París.

Gordon, Colin, 1987, "The Soul of the Citizen: Max Weber and Michel Foucault on Rationality and Government", en Saim Whimster y Scott Lash (comps.), Max Weber, Rationality and Modernity, Allen and Unwin, Londres, pp. 293316.

Gordon, Colin, 1991, “Governmental Rationality: An Introduction”, en Graham Burchell, Colin Gordon y Peter Miller (comps.), The Foucault Effect: Studies in Governmentality, University of Chicago Press, Chicago, pp. 1-52.

Lagasnerie, Geoffroy de, 2015, La última lección de Michel Foucault. Sobre el neoliberalismo, la teoría y la política, trad. Horacio Pons, Fondo de Cultura Económica, Buenos Aires.

Laval, Christian y Pierre Dardot, 2013, La nueva razón del mundo. Ensayo sobre la sociedad neoliberal, trad. Alfonso Díez, Gedisa, Barcelona.

Lemke, Thomas, 2017, Introducción a la biopolítica, trad. Lidia Tirado Zedillo, Fondo de Cultura Económica, México.

Méndez, Pablo Martín, 2014, "Edmund Husserl en el ordoliberalismo alemán. Extrañezas, resonancias y actitudes", Valenciana. Estudios de Filosofía y Letras, año 7, no. 13, pp. 145-172, <https://doi.org/10.15174/rv.v0i13.48>.

Méndez, Pablo Martín, 2015, "Foucault y la Aufklärung, o el trabajo de sí como legado crítico", Cuestiones de Filosofía, vol. 17, pp. 139-162, <https://doi. org/10.19053/01235095.4292>.

Méndez, Pablo Martín, 2017a, "Neoliberalismo y liberalismo. La libertad como problema de gobierno", Postdata. Revista de Reflexión y Análisis Político, vol. 23, no. 2, pp. 551-582.

Méndez, Pablo Martín, 2017b, "Pensar al neoliberalismo como racionalidad de gobierno. El valor del archivo", El Arco y la Lira. Tensiones y Debates, no. 5, pp. 87-102.

Revista de Filosofía Diánoia, vol. 65, no. 84 (mayo-octubre de 2020)

e-ISSN: 1870-4913 • DOI: https://doi.org/10.22201/iifs.18704913e.2020.84.1603 
Morey, Miguel, 2008, "La cuestión del método", en Michel Foucault, Tecnologías del yo y otros textos afines, trad. Mercedes Allendesalazar, Paidós, Buenos Aires, 2008, pp. 9-44.

Polanyi, Karl, 2001, The Great Transformation. The Political and Economic Origins of Our Time, Beacon Press, Boston.

Rosanvallon, Pierre, 2006, El capitalismo utópico. Historia de la idea de mercado, trad. Viviana Ackerman, Nueva Visión, Buenos Aires.

Recibido el 23 de enero de 2019; revisado el 24 de septiembre de 2019; aceptado el 12 de enero de 2020. 